\title{
Suppression of phosphatase and tensin homolog protects insulin-resistant cells from apoptosis
}

\author{
DI-FEI WANG, HUI-JING YANG, JIAN-QIU GU, YAN-LI CAO, \\ XIN MENG, XIAO-LI WANG, YI-CHEN LIN and MING GAO \\ Department of Geriatric Endocrinology, The First Affiliated Hospital of China Medical University, \\ Shenyang, Liaoning 110001, P.R. China
}

Received February 24, 2014; Accepted December 12, 2014

DOI: $10.3892 / \mathrm{mmr} .2015 .3771$

\begin{abstract}
In the present study, a glucosamine-induced model of insulin-resistant skeletal muscle cells was established in order to investigate the effect of inhibition of phosphatase and tensin homolog (PTEN)/5'-adenosine monophosphate-activated protein kinase (AMPK) on these cells. The glucosamine-induced insulin-resistant skeletal muscle cells were produced and the rate of glucose uptake was measured using the glucose oxidase-peroxidase method. The expression levels of PTEN and phosphorylated PTEN (p-PTEN) were assessed using western blotting. Glucose transporter 4 (GLUT4) translocation was detected by immunofluorescence. Cell apoptosis was evaluated using flow cytometry. Following insulin stimulation, the rate of glucose uptake was significantly reduced in the cells with glucosamine-induced insulin-resistance in comparison with those in the control group. The expression and translocation of GLUT4 were reduced in the insulin-resistant muscle cells. By contrast, the expression of PTEN and p-PTEN as well as apoptosis were significantly increased. Following treatment with bisperoxopicolinatooxovanadate (BPV) or metformin in the insulin-resistant skeletal muscle cells, there was an increase in the rate of glucose uptake, an increase in GLUT4 expression and its translocation, a reduction in the expression of PTEN and p-PTEN, and a decrease in cell apoptosis compared with untreated insulin-resistant cells. Glucosamine may be used to produce an effective model of insulin-resistant skeletal muscle cells. Cells with glucosamine-induced insulin-resistance exhibited a reduced expression of GLUT4 and dysfunction in GLUT4 translocation, as well as increased activation of PTEN and increased cell apoptosis. Inhibition of PTEN or
\end{abstract}

Correspondence to: Dr Di-Fei Wang, Department of Geriatric Endocrinology, The First Affiliated Hospital of China Medical University, 155 North Nanjing, Shenyang, Liaoning 110001, P.R. China E-mail: wdf81m@163.com

Key words: insulin resistance, skeletal muscle cells, phosphatase and tensin homolog, glucosamine its upstream regulator, AMPK, protects glucosamine-induced insulin-resistant skeletal muscle cells from apoptosis.

\section{Introduction}

Glucose metabolism is an important component of skeletal muscle metabolism. Approximately $70-85 \%$ of glucose is utilized by skeletal muscle. Metabolic dysfunction of skeletal muscle is associated with a number of human diseases. One of the pathophysiological foundations of type 2 diabetes mellitus (T2DM) is reduced glucose utilization by skeletal muscles. High concentrations of insulin, and free fatty acid (FFA)- and palmitic acid-induced skeletal muscle cell insulin resistance are commonly used experimental models of insulin resistance (1-3).

In clinical practice, glucosamine is used to treat bone and joint diseases. Long-term glucosamine treatment has been shown to lead to insulin resistance in patients (4). Rats fed with oral glucosamine have been used as an animal model of insulin resistance $(5,6)$. Glucosamine may also be used to induce insulin resistance in liver cells (7). However, whether glucosamine induces insulin resistance in skeletal muscle cells remains elusive.

Numerous factors may also lead to reduced glucose utilization in skeletal muscles. One such factor may be the decrease in the expression and membrane translocation of glucose transporter 4 (GLUT4), which are regulated by the 5 '-adenosine monophosphate-activated protein kinase (AMPK) and the phosphoinositide 3-kinase (PI3K)/phosphatase and tensin homolog (PTEN) pathways (8). The PI3K/protein kinase $\mathrm{B}$ (Akt) pathway is involved in a variety of biological activities, such as cell apoptosis and cell proliferation $(9,10)$. PTEN negatively regulates intracellular levels of phosphatidylinositol-3,4,5-trisphosphate (PIP3) and functions as a tumor suppressor by negatively regulating $\mathrm{AKT} / \mathrm{PKB}$ signaling $(11,12)$. PTEN is also a downstream regulator of AMPK (13). However, the roles of the PI3K/PTEN pathway and AMPK in the development of insulin resistance in skeletal muscle cells remain elusive.

In the present study, a glucosamine-induced skeletal cell model of insulin resistance was established. The expression and translocation of GLUT4, as well as the expression of PTEN and phosphorylated PTEN (p-TEN) and cellular apoptosis 
were measured in these cells. In order to better understand the role of PTEN in insulin-resistant skeletal muscle cells, bisperoxopicolinatooxovanadate (BPV), a PTEN inhibitor, and metformin, an AMPK activator, were administered to the cells.

\section{Materials and methods}

Materials. Dulbecco's modified Eagle's medium (DMEM, low glucose) was obtained from GE Healthcare Life Sciences (Logan, UT, USA), fetal bovine serum was obtained from TransGen, (Beijing, China), Glucose Oxidase Assay kit was obtained from Shanghai Rongsheng-biotech, (Shanghai, China), the Annexin V/Propidium Iodide (PI) Detection kit was obtained from Beijing Biosea Biotechnology Co., Ltd. (Beijing, China), the cell lysis buffer and the bicinchoninic acid (BCA) kits were obtained from Beyotime Institute of Biotechnology (Shanghai, China) and the rabbit polyclonal anti-GLUT4 (cat. no. 21619) antibody was obtained from Signalway Antibody, LLC (College Park, MD, USA).

Cell culture. Rat primary skeletal muscle cells (L6; American Type Culture Collection, Manassas, VA, USA) were provided by Dr Yudong Hou from China Medical University (Shenyang, China). Cells were cultured in DMEM supplemented with $10 \%$ fetal bovine serum in a $5 \% \mathrm{CO}_{2}, 37^{\circ} \mathrm{C}$ incubator.

Establishment of the insulin-resistant skeletal muscle cell model. In order to establish the insulin-resistant skeletal muscle cell model, skeletal muscle cells were seeded at $1.5 \times 10^{4}$ cells/well in 96 -well plates. Cells were maintained in DMEM with a high-glucose concentration (4.5 g/l) supplemented with $10 \%$ (v:v) fetal bovine serum and antibiotics (100 U/ml penicillin and $100 \mu \mathrm{g} / \mathrm{ml}$ streptomycin; Gibco Life Technologies, Carlsbad, CA, USA) as previously described. Briefly, cells were divided into control and glucosamine (Beyotime Institute of Biotechnology) groups. Various concentrations of glucosamine $(9,18,27$ or $36 \mathrm{mmol} / \mathrm{l})$ were used. Each group contained six replicates and cells were cultured for $12 \mathrm{~h}$. Glucose concentrations were detected with a glucose detection kit-Glucose Oxidase Method using a microplate reader (ELx808IU; Bio-Tek Instruments, Winooski, VT, USA). Glucose concentrations were also measured at $30 \mathrm{~min}$ post-insulin administration $\left(1 \times 10^{-7} \mathrm{~mol} / \mathrm{l}\right.$, Novo Nordisk, China). The glucose uptake rate was calculated as follows: Difference in glucose concentration prior to and following insulin treatment / glucose concentration prior to insulin treatment.

Glucose measurement. The glucose concentration of the cell culture medium was measured. Glucose concentrations were initially tested before cells were cultured. Following cell adherence, cells were divided into four groups, namely: Blank control, glucosamine $(18 \mathrm{mmol} / \mathrm{l})$, metformin $(8 \mathrm{mmol} / \mathrm{l})$ and BPV (38 nmol/l). Cells were treated for $12 \mathrm{~h}$ and glucose concentrations were measured in each well. Cells were then further treated with insulin $\left(1 \times 10^{-7} \mathrm{~mol} / \mathrm{l}\right)$ for $0.5 \mathrm{~h}$ and glucose concentrations were measured again. Glucose concentration was determined using a glucose oxidase (glucose detection) kit.
Detection of cell apoptosis. The cell apoptosis rate was detected using an apoptosis kit. Following trypsinization (Gibco Life Technologies), $500 \mu 1$ cells $\left(1 \times 10^{6} / \mathrm{ml}\right)$ were centrifuged at $300 \mathrm{xg}$ at $4^{\circ} \mathrm{C}$ for $10 \mathrm{~min}$. The supernatant was discarded and the pellet was resuspended in $200 \mu \mathrm{l}$ binding buffer from the apoptosis detection kit, and $10 \mu \mathrm{l}$ Annexin V was then added. Cells were kept in the dark at $4^{\circ} \mathrm{C}$ for $30 \mathrm{~min}$. Binding buffer $(300 \mu \mathrm{l})$ and $5 \mu \mathrm{l}$ PI reagent were added and the apoptotic rate was measured by flow cytometry(FACS LSR II; BD Biosciences, Franklin Lakes, NJ, USA).

Western blot analysis. Cell lysates were collected using a cell lysis buffer (Beyotime Institute of Biotechnology) and protein was quantified using the BCA kit. Protein was then separated by SDS-PAGE (12\% separation gel and 5\% stacking gel; Seebio Biotech, Inc., Shanghai, China) for 2 h $20 \mathrm{~min}$. Samples were then damp-dry transferred for 45 min onto a polyvinylidene difluoride membrane. The membrane was blocked with $5 \%$ bovine serum albumin overnight. Samples were washed with Tris-buffered saline with Tween-20 (TBST; Seebio Biotech, Inc.) and membranes were incubated for $1 \mathrm{~h}$ with rabbit polyclonal primary antibodies [p-PTEN $(1: 1,00$; cat. no. 11062), PTEN (1:1,00; cat. no. 32606) (Signalway Antibody, LLC) and $\beta$-actin (1:1,500; cat. no. 63508; ZSBIO, Beijing, China)]. The membrane was then washed with TBST, following which horseradish peroxidase-labeled secondary antibodies (1:10,000, cat. nos. 12465, 21150 and 42602) were added and incubated for $40 \mathrm{~min}$. Samples were washed with TBST and the membrane was developed with enhanced chemiluminescence (Applygen Technologies, Inc., Beijing, China). All primary antibodies were purchased from SAB Company (College Park, MD, USA). Secondary antibodies were purchased from Beijing Zhongshan Golden Bridge Biotechnology Co, Ltd. (Beijing, China). ImageJ 1.48 software (National Institutes of Health, Bethesda, MD, USA) was used for gray scale value analysis.

Immunofluorescent staining and fluorescence microscopy. For immunostaining, cells were seeded onto coverslips in six-well plates at a concentration of $1 \times 10^{5}$ cells/well. Following attachment, cells were treated according to the group they were in. At the end of each treatment, cells were fixed with fixation buffer (Beyotime Institute of Biotechnology) for $10 \mathrm{~min}$ and blocked with blocking buffer at $4^{\circ} \mathrm{C}$ overnight. Cells were then sequentially incubated with a primary antibody to GLUT4 (diluted at 1:1,000) and a secondary antibody (fluorescein isothiocyanate-labeled goat anti-rabbit immunoglobulin G (Beyotime Institute of Biotechnology). Nuclei were stained with Hoechst 33342 (Beyotime Institute of Biotechnology). In between these steps, cells were washed with TBST. Coverslips were then removed from the plates, which were mounted with mounting liquid (Beyotime Institute of Biotechnology). Images were captured with a fluorescence microscope (Olympus Corporation, Tokyo, Japan). ImageJ software was used for gray scale value analysis.

Statistical analysis. Statistical analysis was performed using analysis of variance or the $\chi^{2}$ test. All data are presented as the mean \pm standard deviation. Statistical analyses were conducted using GraphPad Prism 4.0 for Mac (GraphPad Software, Inc., 
Table I. Glucose uptake rate following $12 \mathrm{~h}$ culture and insulin stimulation.

\begin{tabular}{|c|c|c|c|c|}
\hline \multirow[b]{2}{*}{ Treatment } & \multicolumn{4}{|c|}{ Group } \\
\hline & Control & Glucosamine & $\begin{array}{l}\text { Glucosamine } \\
\text { +metformin }\end{array}$ & $\begin{array}{c}\text { Glucosamine } \\
+\mathrm{BPV}\end{array}$ \\
\hline $0 \mathrm{~h}(\mathrm{n} 1)(\mathrm{mmol} / \mathrm{l})$ & $5.60 \pm 0.17$ & $5.70 \pm 0.19$ & $6.39 \pm 0.33$ & $5.68 \pm 0.17$ \\
\hline $12 \mathrm{~h}(\mathrm{n} 2)(\mathrm{mmol} / \mathrm{l})$ & $5.33 \pm 0.09$ & $5.90 \pm 0.09$ & $5.55 \pm 0.13$ & $5.30 \pm 0.19$ \\
\hline 30 min insulin $(\mathrm{n} 3)(\mathrm{mmol} / \mathrm{l})$ & $3.75 \pm 0.07$ & $5.44 \pm 0.07$ & $3.98 \pm 0.57$ & $3.53 \pm 0.14$ \\
\hline $12 \mathrm{~h}$ glucose uptake rate $(\mathrm{n} 1-\mathrm{n} 2) / \mathrm{n} 1(\%)$ & $4.74 \pm 3.97$ & $-1.95 \pm 5.00$ & $13.00 \pm 2.71$ & $9.82 \pm 0.69$ \\
\hline 30 min insulin glucose uptake rate (n1-n3)/n1 (\%) & $32.97 \pm 2.71$ & $5.95 \pm 4.30$ & $37.53 \pm 10.71$ & $39.92 \pm 0.99$ \\
\hline
\end{tabular}

$\mathrm{n} 1$, glucose concentrations in culture media prior to cells being cultured; $\mathrm{n} 2$, glucose concentrations in culture media after cells were cultured for $12 \mathrm{~h} ; \mathrm{n} 3$, glucose concentrations of culture media after cells were cultured in the presence of insulin $\left(1 \times 10^{-7} \mathrm{~mol} / \mathrm{l}\right)$ for half an hour. BPV, bisperoxopicolinatooxovanadate.

A

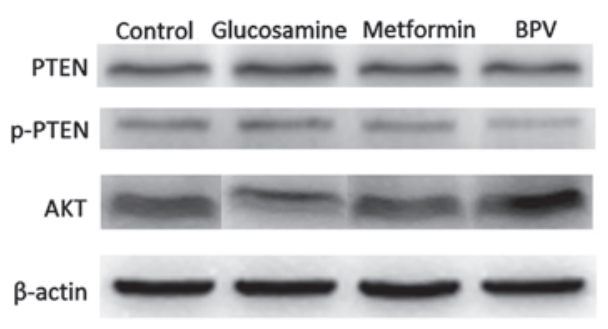

B

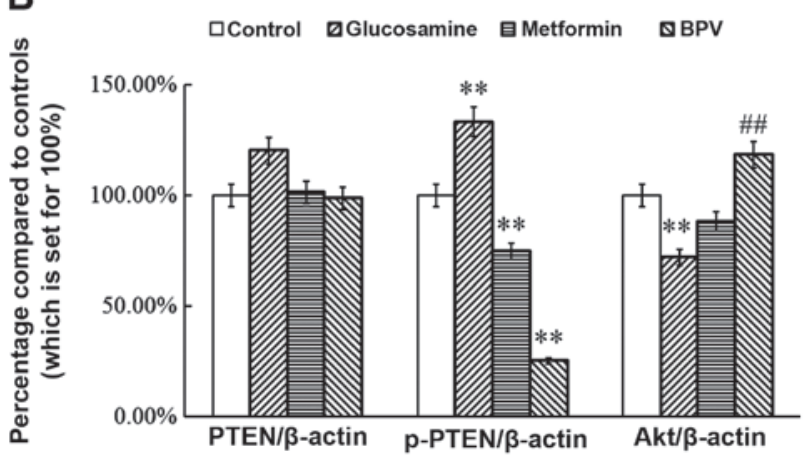

Figure 1. Expression of PTEN, p-PTEN and AKT in skeletal muscle cells. (A) Representative western blot showing expression of PTEN, p-PTEN and AKT expression. Image J software was used for gray scale value analysis. Similar results were obtained from four individual experiments. (B) Semi-quantitative data from four individual experiments. Percentage of gene of interest compared with reference gene ( $\beta$-actin). ${ }^{* *} \mathrm{P}<0.01$, compared with the control group and ${ }^{\# \#} \mathrm{P}<0.01$, compared with the glucosamine group. p-PTEN, phosphorylated phosphatase and tensin homolog; BPV, bisperoxopicolinatooxovanadate.

La Jolla, CA, USA). P $<0.05$ was considered to indicate a statistically significant difference.

\section{Results}

Establishment of glucosamine-induced model of insulin-resistant skeletal muscle cells. Various concentrations of glucosamine $(9,18,27$ or $36 \mathrm{mmol} / \mathrm{l})$ were used in order to investigate the efficiency of particular doses in inducing insulin resistance in skeletal muscle cells. Measurement of the glucose uptake rate showed that the $18 \mathrm{mmol} / \mathrm{l}$ dose of glucosamine produced the most marked induction of insulin resistance. Therefore, $18 \mathrm{mmol} / \mathrm{l}$ of glucosamine was selected as for use in subsequent experiments. The original difference in glucose concentration between the control and glucosamine groups was not significant $(\mathrm{P}>0.05)$. Following treatment with insulin for $30 \mathrm{~min}$, the concentration of glucose in the control group was significantly decreased and the glucose uptake rate was significantly increased $(32.97 \pm 2.71$ vs. $5.95 \pm 4.30 \%)$. The concentration of glucose in the medium following culture was also significantly decreased $(\mathrm{P}<0.01 ; 3.75 \pm 0.07$ vs. 5.60 \pm 0.17 ; Table I). In the glucosamine group, the glucose concentrations were also decreased, and the difference in glucose concentrations prior to and following insulin stimulation was also statistically significant $(\mathrm{P}<0.05 ; 5.70 \pm 0.19$ vs. 5.44 \pm 0.07 ; Table I). These results suggested that an insulin-resistance model of skeletal muscle cells was successfully established in the present study.

Metformin or BPV treatment inhibits the activation of PTEN and regulates the expression of $A K T$ in insulin-resistant skeletal muscle cells. BPV is a known PTEN inhibitor and its effect on $\mathrm{C} 2 \mathrm{C} 12$ myoblast migration and differentiation has previously been described (14). Metformin is an AMPK inhibitor and is the most widely used anti-diabetic drug worldwide. There is increasing evidence for the potential efficacy of this agent as an anti-cancer drug (15). In order to confirm the effect of inhibition of PTEN in an insulin-resistant model of skeletal muscle cells, the effect of BPV and metformin on the activation of PTEN was investigated. The results demonstrated that glucosamine activates PTEN in insulin-resistant skeletal muscle cells $(\mathrm{P}<0.01$; Fig. 1). However, the levels of p-PTEN in the metformin and BPV groups were significantly lower than those in the control group $(\mathrm{P}<0.01)$. PTEN expression was not affected by treatment with any of the agents used ( $\mathrm{P}>0.05$; Fig. 1). The results also showed that the expression of AKT was reduced in the glucosamine group $(\mathrm{P}<0.01)$, and that this change was reversed by treatment with metformin or BPV, suggesting that inhibition of PTEN or its upstream regulator affect the expression of $\mathrm{AKT}(\mathrm{P}<0.01$; Fig. 1). These results indicate that metformin and BPV treatment inhibits the activation of PTEN in insulin-resistant skeletal muscle cells. 
A
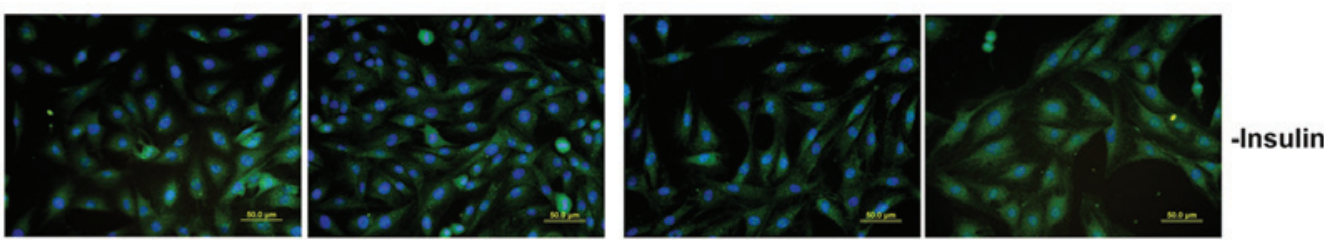

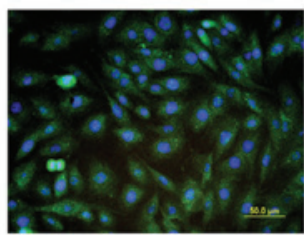

Control

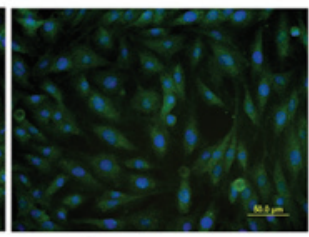

Glucosamine

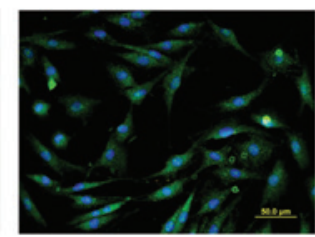

Glucosamine+metformin

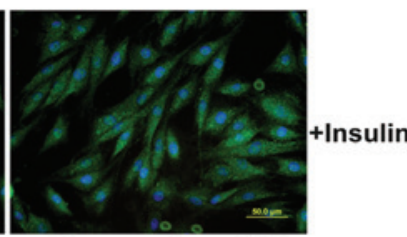

Glucosamine +BVP
$\mathbf{B}$

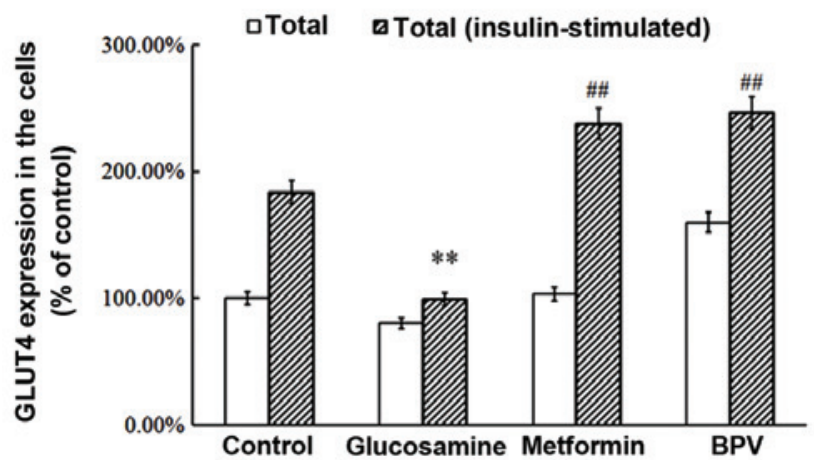

C

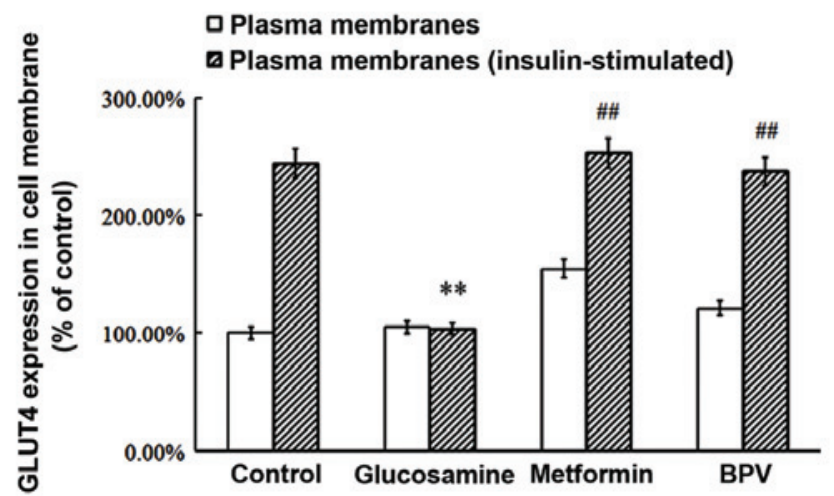

Figure 2. GLUT4 expression and translocation. (A) GLUT4 expression and translocation were detected by immunofluorescence and fluorescence microscopy imaging. ImageJ software was used for gray scale value analysis of the total cells and the cell membrane. Blue fluorescence staining, DAPI; green fluorescence staining, GLUT4. Experiments were performed four times. Scale bar, $50 \mu \mathrm{m}$. (B) Total amount of GLUT4 in the cells was quantified using gray scale values. (C) Amount of GLUT4 in cell membrane quantified using gray scale values. ${ }^{* *} \mathrm{P}<0.01$ compared with the control group and ${ }^{\# \#} \mathrm{P}<0.01$ compared with the glucosamine group. GLUT4, glucose transported 4; BPV, bisperoxopicolinatooxovanadate.
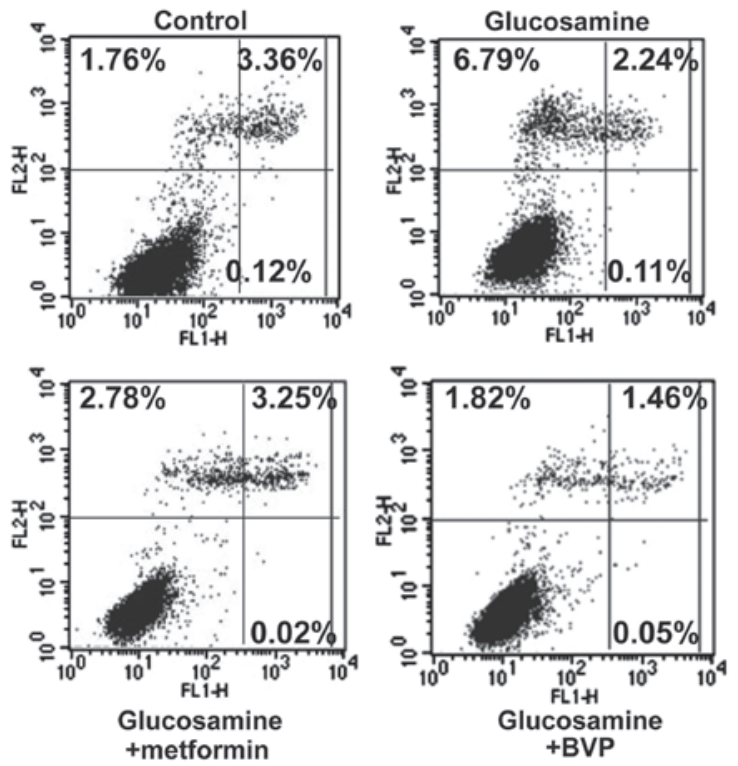

Figure 3. Cell apoptosis was detected by flow cytometry. Upper left, dead cells; upper right, late apoptotic cells; lower right, early apoptotic cells; lower left, living cells. Similar results were obtained from four individual experiments. BPV, bisperoxopicolinatooxovanadate.

Metformin and BPV reduce glucose uptake in insulin-resistant skeletal muscle cells. In order to determine whether the inhibition of PTEN and its upstream regulator reverses glucose uptake, BPV and metformin were used to treat the insulin-resistant skeletal muscle cells. Following treatment with insulin, the rate of glucose uptake in the glucosamine 
group was significantly lower than that in the control group $(5.95 \pm 4.30$ vs. $32.97 \pm 2.71 ; \mathrm{P}<0.01)$. Metformin or BPV treatment increased the glucose uptake rate in cells exhibiting glucosamine-induced insulin-resistance $(37.53 \pm 10.71$ vs. $5.95 \pm 4.30$; and $39.92 \pm 0.99$ vs. $5.95 \pm 4.30$, respectively; $\mathrm{P}<0.05$; Table I). Metformin or BPV treatment did not affect the glucose uptake rate in the control group $(37.53 \pm 10.71$ vs. $32.97 \pm 2.71$; and $39.92 \pm 0.99$ vs. $32.97 \pm 2.71$, respectively; $\mathrm{P}>0.05$; Table I).

Metformin and BPV increase GLUT4 expression and translocation in insulin-resistant skeletal muscle cells. GLUT4 is known to be important in regulating glucose uptake. Therefore, the expression and translocation of GLUT4 were measured in insulin-resistant skeletal muscle cells. Glucosamine treatment was shown to significantly reduce the expression of GLUT4 compared with that in the control group $(\mathrm{P}<0.01$; Fig. $2 \mathrm{~A}$ and $\mathrm{B}$ ). Metformin or BPV treatment reversed this change in GLUT4 expression, which had been induced by glucosamine $(\mathrm{P}<0.01$; Fig. $2 \mathrm{~A}$ and $\mathrm{B})$. In addition, the translocation of GLUT4 from the intracellular membrane to the plasma membrane following insulin stimulation was reduced by administration of glucosamine (Fig. 2A and C). By contrast, this reduction in GLUT4 translocation was reversed by treatment with metformin or BPV. These results suggested that the inhibition of PTEN may reverse the reduction in expression and translocation of GLUT4, which is induced by glucosamine.

Metformin or BPV treatment reduces glucosamine-induced cell apoptosis in insulin-resistant skeletal muscle cells. Glucosamine administration led to a significant increase in cell apoptosis (late apoptotic + dead cells; $5.24 \%$ vs 9.14\%, P<0.01; Fig. 3). Metformin or BPV treatment reduced this glucosamine-induced cell apoptosis to $6.05 \%$ and $3.33 \%$, respectively $(\mathrm{P}<0.05$ for metformin, and $\mathrm{P}<0.01$ for BPV; Fig. 3). These results suggested that PTEN inhibition protects the cells against glucosamine-induced apoptosis.

\section{Discussion}

In the present study, a glucosamine-induced rat model of insulin-resistance in primary skeletal muscle cells was established. It was shown that the uptake of glucose and insulin-stimulated GLUT4 translocation were significantly reduced in the insulin resistance model compared with control cells. The expression and translocation of GLUT4, and AKT expression were reduced in skeletal muscle cells with glucosamine-induced insulin resistance. In addition, the administration of BPV increased the rate of glucose uptake and the expression and translocation of GLUT4.

Within the skeletal muscle, cardiac muscle and adipose tissue, GLUT4 functions as a transporter that conveys glucose from the extracellular to the intracellular environment (16). In insulin resistance, GLUT4 activity and translocation are known to be reduced (17). Multiple cellular signal transduction pathways regulate GLUT4 expression and translocation (18). Among them, the PI3K/AKT pathway is an important pathway for insulin signaling. The AKT pathway promotes cell growth and proliferation, and stimulates GLUT4 to translocate to the plasma membrane, thus promoting glucose uptake $(19,20)$. The results of the present study suggested that the increased expression of PTEN may induce a reduction in the expression and translocation of GLUT4 in glucosamine-induced insulin-resistant skeletal muscle cells. This finding is in accordance with the negative regulation of the PI3K/AKT pathway by PTEN.

Furthermore, the administration of the AMPK agonist metformin was shown to increase the rate of glucose uptake and of GLUT4 expression and its translocation. In addition, the results demonstrated that metformin increased the expression of AKT and reduced the expression of PTEN and p-PTEN. The hypoglycemic mechanism underlying the effects of metformin may also occur through regulation of PTEN, which is a potential downstream regulator of AMPK (13). The results of the present study further support the hypothesis that increased PTEN expression in insulin-resistant skeletal muscle cells may contribute to reduced GLUT4 expression and impaired translocation of this enzyme.

The apoptotic rate was shown to be increased in the insulin-resistant skeletal muscle cells. In addition to promoting glucose uptake and increasing the translocation and expression of GLUT4, BPV and metformin also reduced cell apoptosis. A possible explanation for the reversal of insulin resistance and reduction in apoptosis induced by BPV and metformin may be that it is a result of reducing PTEN and activating the PI3K/AKT pathway. A previous study showed that overexpression of PTEN inhibits AKT activity and induces apoptosis through the PI3K/AKT pathway (21).

In the present study, glucosamine induced insulin resistance in rat skeletal muscle cells. Glucosamine was shown to reduce the expression and translocation of GLUT4, to increase the apoptotic rate as well as the expression of PTEN and p-PTEN, and to decrease AKT expression. Metformin and BPV were shown to increase glucose uptake and GLUT4 expression and translocation, which may protect against apoptosis in glucosamine-induced insulin-resistant skeletal muscle cells.

\section{Acknowledgements}

This study was supported by the Science and Technology projects in Liaoning Province (grant nos. 2012225079 and 20102250002), the Science and Technology projects in Shenyang City (grant no. F13-221-9-02) and the National Natural Science Funds (grant no. 81100216). The authors would like to thank Dr Yifu Guan, Dr Ying Liu, Dr Qiang Bi and Mr. Nanqi Liu of the Biochemistry Department of China Medical University (Shenyang, China), for their professional and technical assistance.

\section{References}

1. McCarthy AM Spisak KO, Brozinick JT and Elmendorf JS: Loss of cortical actin filaments in insulin-resistant skeletal muscle cells impairs GLUT4 vesicle trafficking and glucose transport. Am J Physiol Cell Physiol 291: C860-C868, 2006.

2. Habegger KM Penque BA, Sealls W, Tackett L, Bell LN, Blue EK, Gallagher PJ, Sturek M, Alloosh MA, Steinberg HO, Considine RV and Elmendorf JS: Fat-induced membrane cholesterol accrual provokes cortical filamentous actin destabilisation and glucose transport dysfunction in skeletal muscle. Diabetologia 55: 457-467, 2012.

3. Rando TA and Blau HM: Primary mouse myoblast purification, characterization and transplantation for cell-mediated gene therapy. J Cell Biol 125: 1275-1287, 1994. 
4. Dostrovsky NR, Towheed TE, Hudson RW and Anastassiades TP The effect of glucosamine on glucose metabolism in humans: a systematic review of the literature. Osteoarthritis Cartilage 19: 375-380, 2011.

5. Chien CS, Cheng SC, Wu HT, Tsao CW and Cheng JT: Insulin resistance induced by glucosamine in fructose-fed rats. Horm Metab Res 41: 542-547, 2009.

6. Kang L, Chen CH, Cheng YC, Chang CH, Lee CT, Chang JK, Cheng JT and Chang FM: Glucosamine-induced insulin resistance in ovariectomized rats is relevant to decreasing the expression of glucose transport protein subtype 4 in the skeletal muscle and in increasing the size of pancreatic islets Menopause 19: 496-502, 2012

7. Sakai K and Clemmons DR: Glucosamine induces resistance to insulin-like growth factor I (IGF-I) and insulin in Hep G2 cell cultures: biological significance of IGF-I/insulin hybrid receptors. Endocrinology 144: 2388-2395, 2003.

8. Lee JO, Lee SK, Kim JH, Kim N, You GY, Moon JW, Kim SJ, Park SH and Kim HS: Metformin regulates glucose transporter 4 (GLUT4) translocation through AMP-activated protein kinase (AMPK)-Mediated Cbl/CAP Signaling in 3T3-L1 Preadipocytecells. J Biol Chem 287: 44121-44129, 2012.

9. Meshkani R and Adeli K: Hepatic insulin resistance, metabolic syndrome and cardiovascular disease. Clin Biochem 42 $1331-1346,2009$

10. Joshi A and Ellenson LH: Adenovirus mediated homozygous endometrial epithelial Pten deletion results in aggressive endometrial carcinoma. Exp Cell Res 317: 1580-1589, 2011.

11. Li J, Yen C, Liaw D, Podsypanina K, Bose S, Wang SI, Puc J, Miliaresis C, Rodgers L, McCombie R, et al: PTEN, a putative protein tyrosine phosphatase gene mutated in human brain, breast and prostate cancer. Science 275: 1943-1947, 1997.

12. Nyåkern M, Tazzari PL, Finelli C, Bosi C, Follo MY, Grafone T, Piccaluga PP, Martinelli G, Cocco L and Martelli AM: Frequent elevation of Akt kinase phosphorylation in blood marrow and peripheral blood mononuclear cells from high-risk myelodysplastic syndrome patients. Leukemia 20: 230-238, 2006.
13. Kim SA and Choi HC: Metformin inhibits inflammatory response via AMPK-PTEN pathway in vascular smooth muscle cells. Biochem Biophys Res Commun 425: 866-872, 2012.

14. Dimchev GA, Al-Shanti N and Stewart CE: Phospho-tyrosine phosphatase inhibitor Bpv (Hopic) enhances C2C12 myoblast migration in vitro. Requirement of PI3K/AKT and MAPK/ERK pathways. J Muscle Res Cell Motil 34: 125-136, 2013.

15. Li B, Takeda T, Tsuiji K, Kondo A, Kitamura M, Wong TF and Yaegashi N: The antidiabetic drug metformin inhibits uterine leiomyoma cell proliferation via an AMP-activated protein kinase signaling pathway. Gynecol Endocrinol 29: 87-90, 2013.

16. Zorzano A, Fandos C and Palacin M: Role of plasma membrane transporters in muscle metabolism. Biochem J 349: 667-688, 2000

17. Alkhateeb H, Chabowski C, Glatz JFC, Luiken JFA and Bonen A: Two phases of palmitate-induced insulin resistance in skeletal muscle: impaired GLUT4 translocation is followed by a reduced GLUT4 intrinsic activity. Am J Physiol Endocrinol Metab 293: E783-E793, 2007.

18. Zierath JR, Krook A and Wallberg-Henriksson H: Insulin action in skeletal muscle from patients with NIDDM. Mol Cell Biochem 182: 153-160, 1998.

19. Qu W, Zhao L, Peng X, Yang X, Ying C, Hao L and Sun X: Biphasic effects of chronic ethanol exposure on insulin-stimulated glucose uptake in primary cultured rat skeletal muscle cells: role of the Akt pathway and GLUT4. Diabetes Metab Res Rev 47-53, 2011.

20. Zhou QL, Jiang Z, Mabardy AS, Del Campo ${ }^{\circ} \mathrm{CM}$, Lambright DG, Holik J, Fogarty KE, Straubhaar J, Nicoloro S, Chawla A and Czech MP: A novel pleckstrin homology domain-containing protein enhances insulin-stimulated Akt phosphorylation and GLUT4 translocation in adipocytes. J Biol Chem 285: 27581-27589, 2010

21. Sugimoto N, Miwa S, Ohno-Shosaku T, Tsuchiya H, Hitomi Y, Nakamura H, Tomita K, Yachie A and Koizumi S: Activation of tumor suppressor protein PTEN and induction of apoptosis are involved in cAMP-mediated inhibition of cell number in B92 glial cells. Neurosci Lett 497: 55-59, 2011. 